\title{
The Important of Great Storytelling in Malaysia Animation Industries
}

\author{
Muhammad Nurakram Bin Mohammed Ghazali, Dahlan Abdul Ghani
}

\begin{abstract}
Malaysian animation industry have successfully become one of the main media in promoting Malaysian culture especially to local people. The combination of Malaysia unique traditional and modern culture in animation seems to become one of the key factors. One of Malaysia local animation studios known as Les Copaque is the closest model that we can see to use our unique culture in their animation series called Upin Dan Ipin. However, unique culture and animation without proper storytelling will lead to nothing. Therefore, this research is to study on how important is storytelling in creating a good animation that can make an impact to a viewer and memorizing how great the story is.
\end{abstract}

Keywords: Storytelling, traditional and modern culture, Upin dan Ipin, Les Copaque, key, memorizing.

\section{INTRODUCTION}

\subsection{Background of research}

Animation has become one of the main media in spreading news, story, and educational across the world. In the past few years, Malaysia animation industry has grown stronger and become a main platform in educating the public about culture, religious and life style. The only reason why the animation is succeeding or not it's because of the storytelling itself. Storytelling is the most important element that every animator and director need to understand in order to come out with a super strong animation. However, is not an easy task to come out with a great storytelling, there is a lot of research and experiment need to be done or else the storytelling will not go as we expected. Therefore, in this research we will discuss how to produce a great storytelling especially in Malaysia animation industries.

Storyline and storytelling is an element of story. Story is defined as a series of an event that happen every day in our life whether we notice it or not, it happens every single second in our life even when we sleep. In other word, story also known as narrative, but there are no different at all between story and narrative because "Story" and "narrative" mean the same thing. "Narrative" is simply a more academic term than "story" (Eric Miller, 2011). In stories, there must be storyline and storytelling because story is built from these two components. Storyline is define as a sequence of event that does not need a beginning, middle or an ending. Even more, storyline also didn't need a character.

Other than that, storytelling is the activity of telling or writing stories like an example a mother read a fairy tale

Revised Manuscript Received on September 10, 2019.

Muhammad Nurakram Bin Mohammed Ghazali, University Kuala Lumpur, Malaysian Institute of Information Technology, Jalan Sultan

(Email: ammghazali@gmail.com)

Dahlan Abdul Ghani, University Kuala Lumpur, Malaysian Institute of Information Technology, Jalan Sultan Ismail, Kuala Lumpur, Malaysia

(Email: dahlan@unikl.edu.my) Ismail, Kuala Lumpur, Malaysia.

book for her daughter. That act can be define as storytelling Storytelling is how we as an audience will be introduce to a storyline. It's how the storyline will be related with other storyline. According to (Eric Miller, 2011), he state that storytelling can be define as relating the series of event. In a simple phrase, storytelling is an activity of relating a storyline such as from storyline A, it will lead to storyline B and so on. When it goes to animation, the definition of storytelling is a bit different, but it remains the same activities. The only difference is the way of the act because in animation, we tell the stories trough the visual narrating or visual storytelling which mean the stories is delivered from the movement and the acting in the animation itself.

No doubt storytelling It's a main key in creating an animation film and without it, the animation will become pointless and waste of time. As the co-founder of Pixar Animations studios and president of Pixar and Disney Animation, Ed Catmull(2014) wrote in his book, "the first principle was "Story Is King," by which we meant that we would let nothing-not the technology, not the merchandising possibilities - get in the way of our story. We took pride in the fact that reviewers talked mainly about the way Toy Story made them feel and not about the computer wizardry that enabled us to get it up on the screen. We believed that this was the direct result of our always keeping story as our guiding light." This is the style and philosophies that Pixar animation crew use in every single of their film.

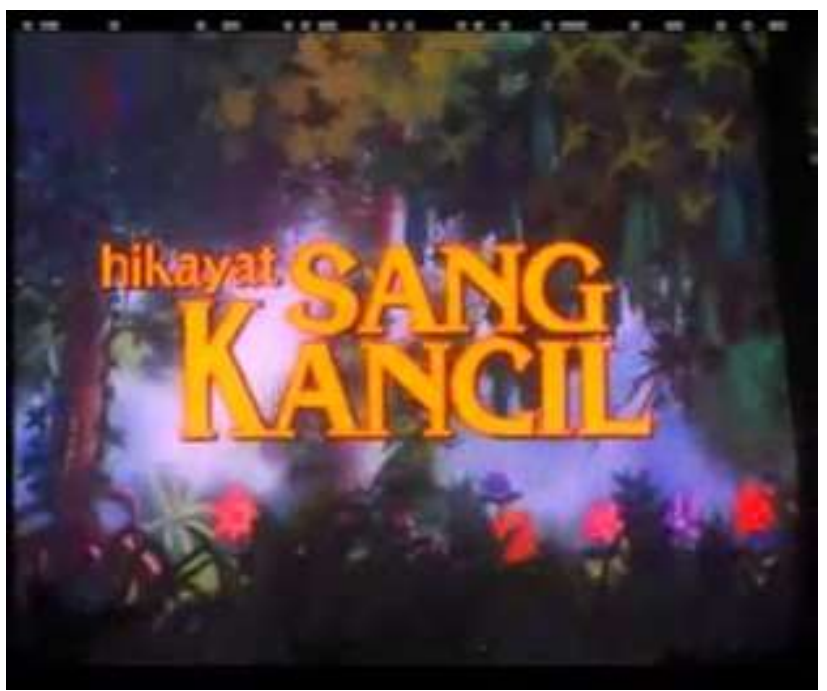

Figure 1.1.1 Malaysian first animation Hikayat Sang Kancil 
It same goes to Malaysia animation industries that started in 1978 when Filem Negara Malaysia (FNM) produce the first local short animated film known as Hikayat Sang Kancil(As shown on Figure 1.1.1). The film was directed by Malaysia's father of animation Hassan Muthalib and was aired on RTM in 1984 as a commercials breaks. Even the film just as commercials break and only four minutes long, it was succeed and make a huge impact to local society especially children's. The film was about a deer with its friends a turtle farming together and a lazy monkey who accidental eats a chili's after he lied to get free fruits. The main point of the film is to educate the society to not being lazy and liars. Even though the story and the animation is simple but it's full of lesson and it's easy to understand.This is why storytelling is really important when it comes to animation. Storytelling must be set as a top priority in order to catch a viewer attentions.

Since that, few film and animated series have been made and all the background stories is based on Malaysian culture, folktale, and lifestyles. In 1998, The first Malaysia animation film, Silat Lagenda that have won the special award on 14-Malaysian Film Festival. It was directed by the same directors of Hikayat Sang Kancil, Hassan Muthalib. However, not every film and animated series that have been made succeed. Silat Lagenda only got MYR141,700 in return after costing around MYR6 million and 2 years of production time. On top of that, it's just aired on cinema for 12 day in 18 cinemas only. Even though the story is good, but not so many people love animations back in the days especially adult because they think animations just for children's. On top of that, the quality of the animation is also not in the highest performance, the movement are stiff and it lack in term of marketing strategy.

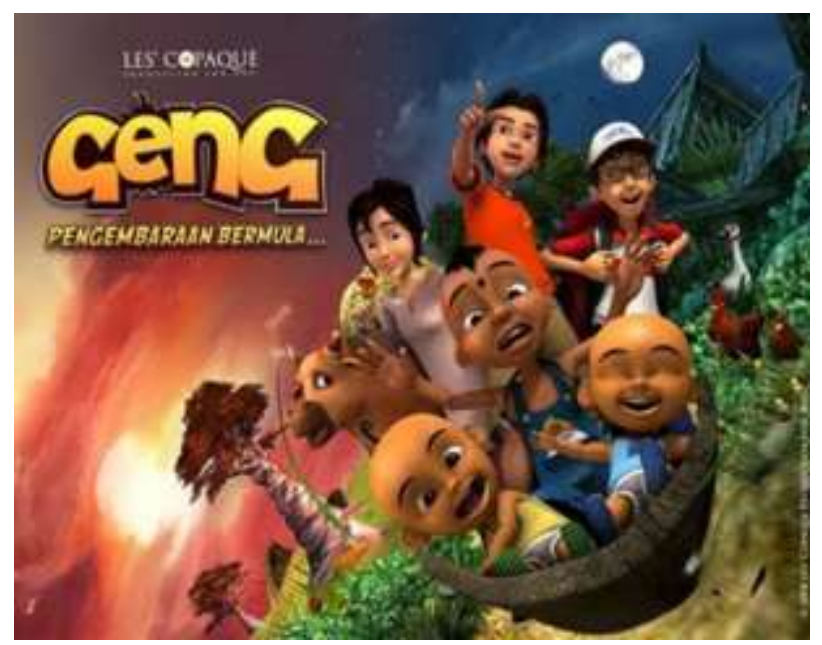

Figure 1.1.2 Geng pengembaraan bermula

However,on 2009 Malaysian animation industry gain the respect from the society when Upin dan Ipin animated series become the national sensation. The series only took 5 minutes long in every episodes and the story is about a twins brother Upin and Ipin live in the village. The content of the stories is simple and only have few shot in one episodes, but what make it a huge success during that time is the way of the storytelling that entertain the viewer and at the same time educate about culture and religious. The series was aired during the holy month of Ramadan and it suit the story background that promoting Islamic Culture. Since that, Upin and Ipin not just famous in Malaysia but that series also famous in Indonesia. Not long after that, Upin and Ipin debut their first film "Geng: Pengembaraan bermula"(As shown on Figure 1.1.2) on February 12, 2009 with MYR4.2 million of budget. The film has been aired for 7 weeks on 56 local cinemas and successfully gain MYR6.3 million during that time. The film officially become top selling in the year of 2009. This film was successful because they have strong base of storytelling that they have shown or introduce in the animated series before the actual film was publish. People already know their flow of storytelling that have cute twins brother character with their other friends who not just Malays but also a Chinese and Indian. This is the way they promoting their film, they not just targeting Malays audience but they also targeting Chinese and Indian audience since Malaysia is known as multiracial country. This is the advantage for every Malaysian who want to make an animation, because we have a variety of culture that we can make as a base storytelling.

\section{LITERATURE REVIEW}

\subsection{Introduction}

Storytelling is the element of story that can be define as relating the series of event (Eric Miller, 2011). In animation, storytelling is shown by the movement of the character that are relating in the stories. Storytelling are connected with human life and because of that we need to understand about human emotion, motivation, and, psychology to have a great storytelling. Storytelling is what connects us to our humanity. It is what links us to our past, and provides a glimpse into our future. Since humans first walked the earth, they have told stories (J. Ferreira, 2015).

\subsection{What is lack in Malaysian animation industry}

Other than that, storytelling is also a main ingredient to have a great animation and without it, the animation will look boring and fail to grab the attention of the audience. As we can see, Malaysian first musical animation facing a huge failure after the film, "Oh! La La" only got MYR37 thousand after spending MYR4 million to produce the film. This film are lack in many aspects such as storyline, storytelling, animation principle, character design, and also promotion. The animation looks like 80's and 90's animation in term of quality and it should not happen when you live in 21 century. The character design does not show the element of Malaysian and also look very stiff. This film shows why research is needed to come out with great storytelling as being told by (Hassan Muthalib, 2017), " Attention must be given to story development, script writing, and visual development rather than production design. This will give more impact to the animation."

Even though Upin dan Ipin impress most of Malaysian citizen when the first film (Geng: Pengembaraan bermula) make a debut. They are still lack in term of storytelling because according to (Nur Afifah, 2016), "The Geng Pengembaraan Bermula was listed in the Malaysia Book of

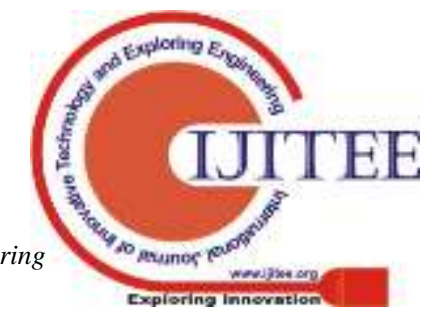


Records as the first 3D Malay animation film in Malaysia. This film has gained public recognition in various film festivals, locally and internationally. Surprisingly, in terms of its narrative, the plot portrayed in this film has lack of continuity issues. The adventure as the main thrust of this film becomes unclear due to its loose narrative." Attention must be given in developing a storytelling rather than anything because Malaysian animation still put the production design as a priority. The awareness must be spread since animation is not easy to make and it involve big amount of budget and time consuming.

\subsection{Rule of great storytelling}

Good animation have good storytelling but great animation have great storytelling. Therefore, there are few rule or tips to produce great storytelling that animators and directors especially in Malaysia need to concern. First thing first, great storytelling has clear structure and purpose, It's how you make people understand about the story and why they need to know about the stories. According to (Brian G, 2016) "By crafting a story that you are passionate to tell because it serves a real purpose, your stories will have bigger impact on the world." Secondly, great storytelling have underdog character. People love to see underdog character that have battling for their life, facing hard life, and struggle. Pixar explains that we as the audience admire a character for trying more than for their success. In other words, it's more about the character's journey than it is their actual destination (Emma Coats, 2012). Great storytelling have the element of surprise and unexpected, it's really important to have this element to make sure the story are not soulless. Finally great storytelling are simple and focus, audience didn't like to take much time to figure out what the story is. Therefore, the stories must simple and focus in order to grab the attention of the audience.

\subsection{Conclusion}

In the previous research that I found about Malaysian animation, most of it are talk about Malaysian citizen who are not have interest to watch local animation because of the influence of overseas animation. According to (Ameir, 2015) he stated that "local audience are not like Japan and other Western country who have big fan base in their country." Other than that, there are few article that talk about why most of Malaysian animation didn't succeed even spending big money on the film but they didn't mention oh how to counter the problem. Most of it just stated about how bad the animation, storyline, and the marketing. However, in this research, we found that Malaysian animation are not too bad because some of it are really succeed even the quality its not like the animation from overseas. Other than that, the main objective of this research also to spread the awareness of the important to have great storytelling to produce an animation that other researcher didn't emphasize. The quality of animation can be improve by have great storytelling and because of this research is important for Malaysia animation industry to improve our quality of animation storytelling

\section{METHODOLOGY \& RESULTS}

\section{1 introduction}

In this chapter, I will explain about the methodology of this research which is the importance of great storytelling in Malaysia Animation Industries. The model that have been choose is from Pixar animation studios that have been use by many organization as their guidance to have a great storytelling. This model is called Pixar's Story Design Philosophy from Cooper Hewitt exhibition. Pixar is known as modern-day storytelling master and it is undeniable because most of their film won many award and give huge impact to audience. Because of that, in this chapter, we will discover how to increase the quality of the storytelling in Malaysia animation industry by following the method that Pixar animation use.

There are few element that are very important to have a great storytelling as being stated by (John Lasseter, 2016) every great story contains three foundation element which is start with compelling narrative, develop memorable and appealing characters, and lastly create a believable world. However to adapt these element in Malaysian animation industry, we need to continuously repeating the cycle of research, collaboration, and iteration until the foundation of the story is strong, and clear. In order to achieve the target to improving our storytelling quality in Malaysia, we need to understand all the element in Pixar Story Design Philosophy. Therefor in this chapter, we will discover how this model work and how it can help Malaysian animation industry in term of storytelling.

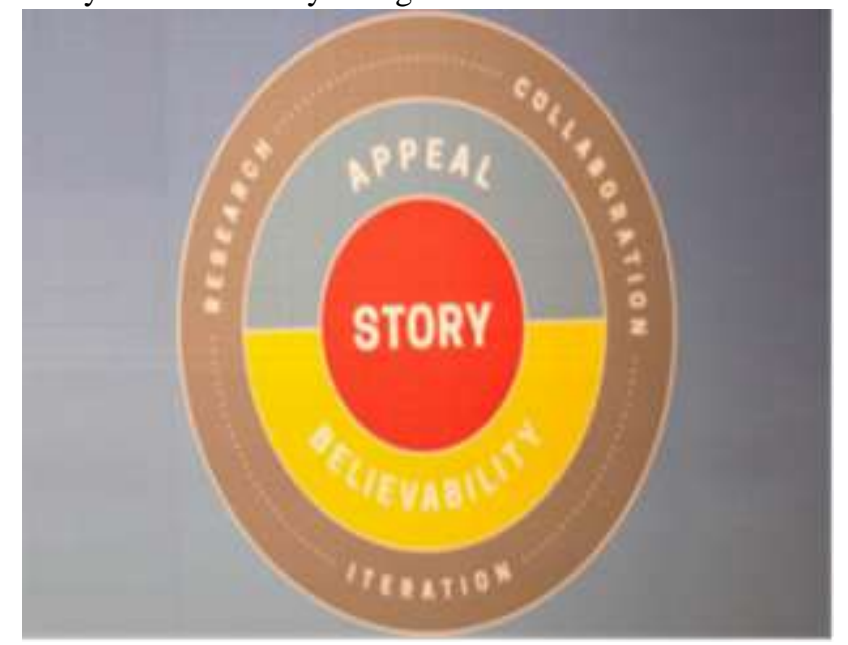

Figure 3.1.1 Pixar story design philosophy

\subsection{Research}

Research is one of the important element not just to identify the story structure but also to understand what the story need. This can be seen when Pixar bring the whole illustrator and technical designer team for the film Cars to a trip to the oldest America's highways to experience, collecting photo and memorabilia along the way. This is the first thing Pixar team do before anything else, they do the research before anything else. Even though the team is full of expertise in the industry, research is still become the top priority to have a solid idea for the storytelling. 


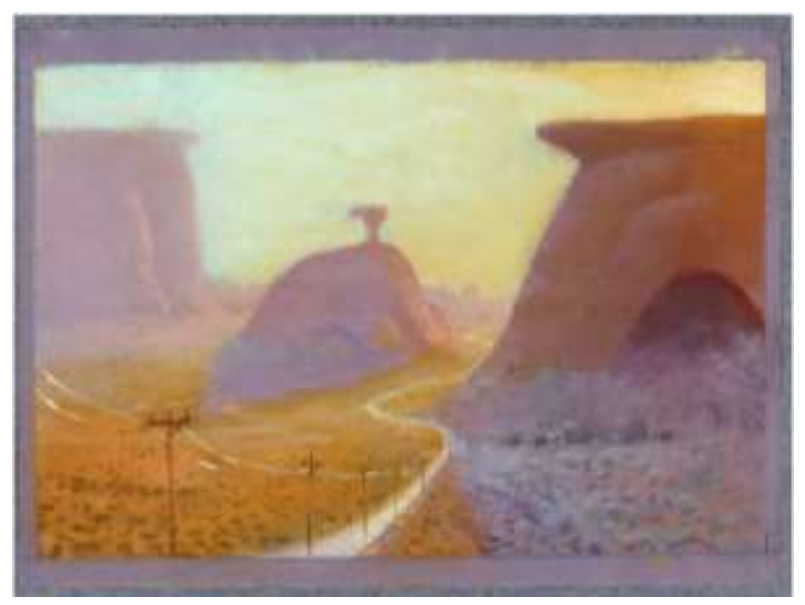

Figure 3.2.1 Bill Cone pastel sketch during research phase for Cars (2006)

During the research phase for Ratatouille, the team met with a woman who lived with 36 rats. The R\&D teams also meeting some expert in the area for Ratatouille film such as the late grate Anthony Bourdain to talk about his experience and memorable meal at the restaurant. According to (Christopher Boone, 2016), Each director spends between four to five months crafting pitches for three separate project ideas. The director then presents each one of these pitches to John Lasseter. Other than that, (Davidson, 2016) also stated "the purpose of the R\&D phase at Disney and Pixar is to deepen the original story idea from the pitch. Even fantasy worlds undergo intense research. The research not only influences how the world is depicted the film, but can also inspire changes in the characters."

\subsection{Collaboration}

Collaboration is define as the action of working with someone to produce something. In animation industry, one company are collaborating with other company to have something new or fresh such as, Pixar animation collaborating with Disney in making their film. As result, the combination of their idea creating or giving something new to the story. According to (Nadidah Coveney, 2017) "Collaboration is the key to your success. It starts with you knowing what you'd like to accomplish while utilizing your resources to achieve a goal. Whether it's in business or managing your career, collaboration is vital to your success". However, in Malaysia, everyone is for himself and there is no company or organization that want to work together as a team. As result, the quality of the storytelling are still the same. Even the audience love it, but it doesn't mean they will love it forever. People are easy to get boring these day, because of that a local company like Les Copaque, Animonsta, or Waw Animation need to work together combining their idea and create something remarkable for animation industry in this country. In addition, Malaysian also have many talented storyteller such as Dato Lat, Hassan Muthalib, Mamat Khalid, and many more. These type of people already spending many years doing a research about Malaysian history and filmmaking and there is no problem if local animation company want to use their idea or collaborate with them in improving the level of our storytelling.

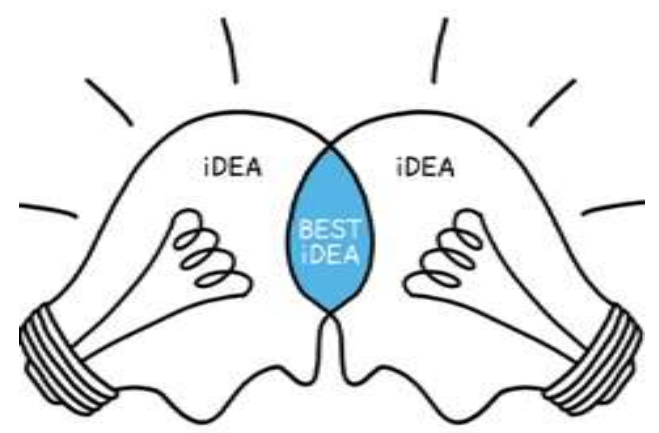

Figure 3.3.1 Idea collaborating concept

\subsection{Iteration}

Base on Cambridge dictionary, iteration is a process of doing something again and again, usually to improve it. It same goes to storytelling when the whole team go through the same process again and again to improve the idea or expand the idea wider. Both Pixar and Disney share the motto of "Be wrong fast" so that they can go back to the same process and identify what is wrong with the story or figure out what is not working with the idea. The faster the teams can find and solve the story problems, the better the process and the film will be in longer time. In Malaysia, we can make Upin Dan Ipin as the example of iteration process. When the series are airing in 2009, they get verity of feedback both positive and negative from the audience. All they did is go trough back to the process and change what need to be change and improve what need to be improved As result, Upin Dan Ipin getting better even they still lack in certain part like visual storytelling. Figure 3.4.1 and figure 3.4.2 the improvement between 2009 Upin dan Ipin series and the upcoming film called Keris Siamang Tungal.

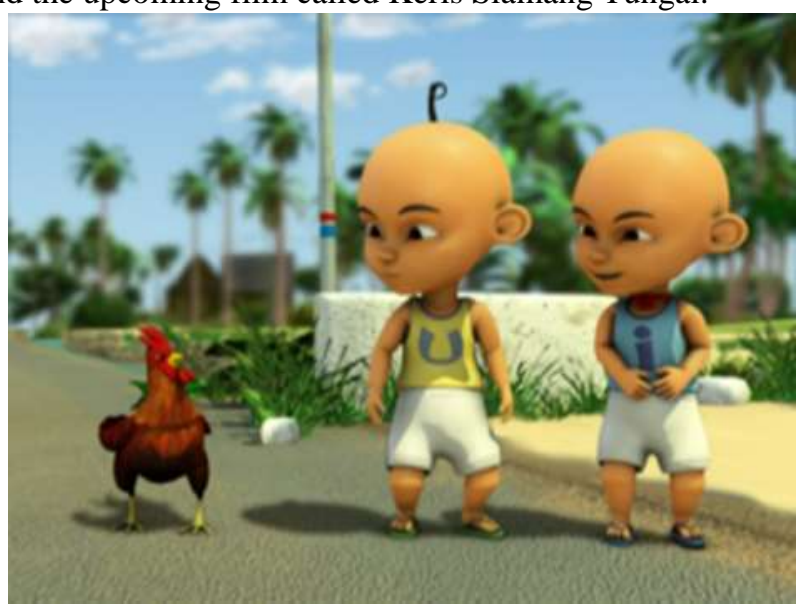

Figure 3.4.1 Upin dan Ipin series in early 2009 


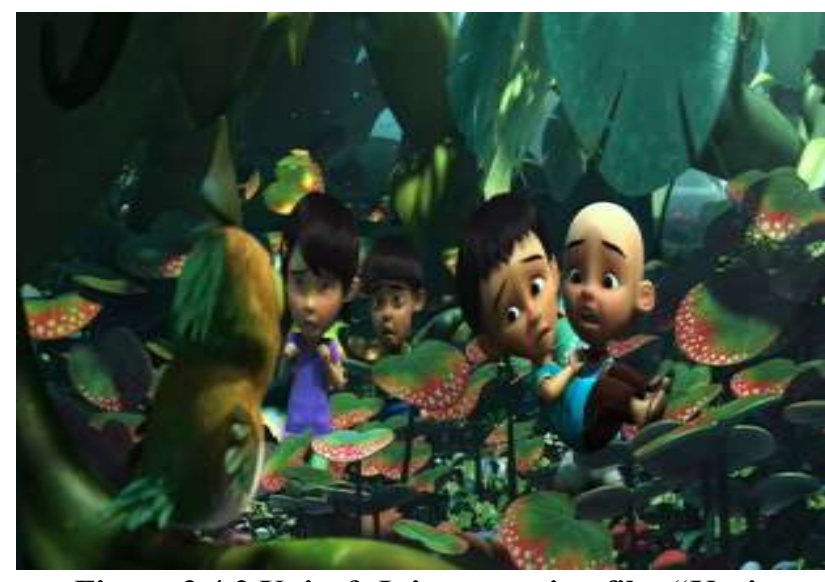

Figure 3.4.2 Upin \& Ipin upcoming film "Keris Siamang Tunggal”

\subsection{Appeal}

Appeal is one of the 12 principle of animation written by Disney animators, Ollie Johnston and Frank Thomas in their book. Appeal in animation is like an actor to have a charisma in their acting to show clearly to audience what are they doing. It's important to show what the character is doing to make the audience understand the story. According to (Amber Rose, 2013) Carl from Disney Pixar 'Up'. Not only does his design appeal to the audience as he looks like a cute grandpa, but his character development does to, he arcs from youthful and adventurous, to an old depressive grouch, to fun loving and fatherly. It's this transition that really appeals to the heart of the audience and makes the film so successful. Therefore, appeal is an element that use to show clearly the visual of the storytelling, to show what is happening and to show what is going to happen. Few animation in Malaysia seems didn't take this element serious in making their animation. One of the animation that seems didn't take this element seriously is the film of $\mathrm{Oh}$ ! $\mathrm{La} \mathrm{La}$. The character does not show enough emotion and clear purpose that make the audience stop watching it. Figure 3.5.1 shows that the character is emotionless and uninteresting.

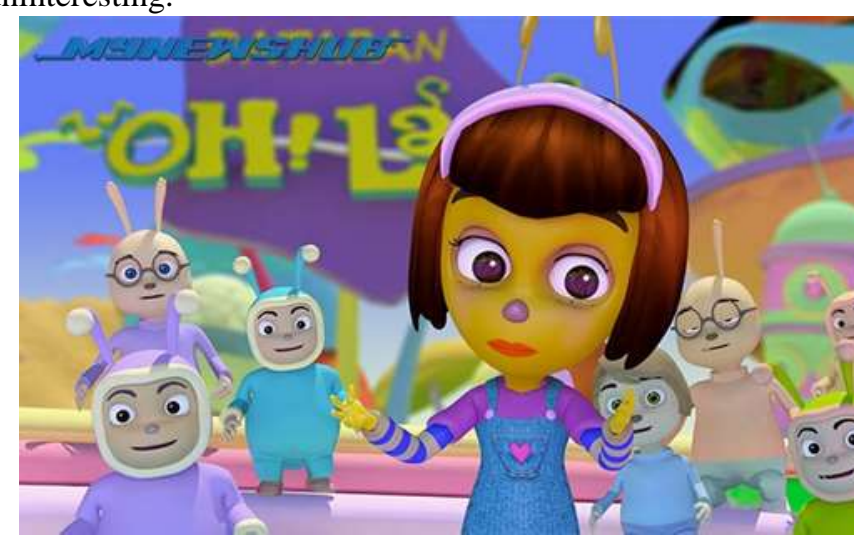

Figure 3.5.1 Emotionless character from Oh! La La film.

However, not all animation company in Malaysia didn't take serious on their visual storytelling. The upcoming movie of Ejen Ali is looking better than ever. The movie trailer that release on July 2018 truly show the level of improvement in Malaysia animation industry. The visual of storytelling getting better as been on figure 3.5.2 the character is not emotionless and had clear action.

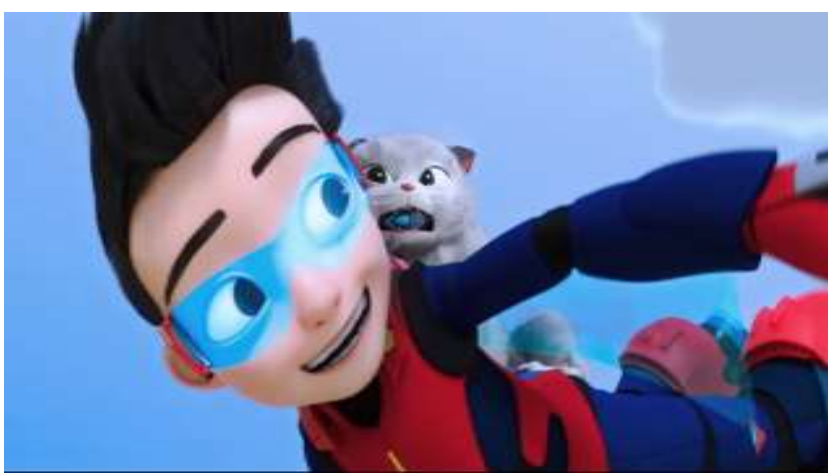

Figure 3.5.2 A shot from Ejen Ali upcoming movies trailer

\subsection{Believability}

Most of Pixar and Disney film are successful is because they make the audience truly believe in the character that has something special like superpower or something. When the character can make the audience laugh, sad, or even angry, that means the character successfully convince the audience mind to believe that the character in hard situation, or the character are truly evil. The main goal of character is to help the audience to connected to the story. When the audience fell connected to the story, they will put themselves in to the situation of the character and make them feel what the character feel. Upin dan Ipin is the best example for Malaysian animation that successfully make the audience believe and connected to the character. The cuteness of the twins sometimes can make the audience laugh and sometimes feel sad for them. Without the element of believability in storytelling, the animation is just an animation without soul. According to (Steven James,2017) "When I'm shaping a story, I continually ask myself, "What would this character naturally do in this situation?" As soon as characters act in ways that aren't believable, either in reference to their characterizations or to the story's progression, the reader loses faith in the writer's ability to tell that story.

\subsection{Story}

(Ed Catmull, 2014) stated that "Story is king and trust the process". The final element of Pixar Story Design Philosophy it's the root of the animation which is story. At the heart of every great film or animation there is a great story that fuel up the entire process. Film and animation are exist because there is a story to tell and show. However to have a great story is not an easy task, it might take several time or even years to have one great story. In every great story, it must have all of its element such as setting, theme, character, plot, and conflict. The combination of all its element will bring you the story that have value and wow factors.

\subsection{Data collecting method}

When conducting this research, various source are being used in collecting the data. All data information are collected from the journals, article, books, and also from the previous research that related to this topic. In addition, I also 
watching few animation short to get some information about this research topic which is The Important of Great Storytelling in Malaysia Animation Industry. I also get the information from the Pixar Story Design Philosophy in how Pixar animation draft their storytelling.

\subsection{Literature study}

All information for this research are collected from the internet. Every information is focusing on the related topic about storytelling. Every journal, article, and book are come from google search. There is also a resource from the previous research collected from the internet. The previous research are about the quality of film language in Geng: Pengembaraan bermula animation film that are related to this research.

\subsection{Observation}

Observation for this research is done by watching animation short's from few animation film on YouTube. The film like Hikayat Sang Kancil, Upin dan Ipin, Ejen Ali, and $\mathrm{Oh}$ ! La La both has positive and negative impact on the quality of storytelling in Malaysia animation industry.

\subsection{Data analysis methods}

After data collection phase is done, all the data are drafted and being analysed to make sure all the information is based on the research area. All of the data then will be combine to fulfil the objective of this research.

\subsection{Conclusion}

Animation industry in Malaysia has growth drastically but there is still a lot to improve especially the storytelling. The Pixar story design philosophy is one of the best model that can be follow as a guideline to have a great storytelling. This model has every single element this research need and also expose a lot about animation story structure. Other than that, it's also work very well for this research because every single element on this model explaining how the process done and how it will work with other process.

\section{REFERENCES}

1. Anne, P. (n.d.). "Webster's New Twentieth Century Dictionary". 2. Retrieved from The Science of Story Structure (\& The Art of Story Telling).

2. Barany, B. (2014, August 8). Writer's Fun Zone. Retrieved from Story is King and Trust the Process, says Pixar: http://writersfunzone.com/blog/2014/08/08/storyis-king-and-trust-the-process-says-pixar/

3. Cambrage Dictionary. (2018). Retrieved from https://dictionary.cambridge.org/dictionary/english/iterati on

4. Catmull, E. (2014). Creativity, Inc . . New York: Random House. ceros. (2016). Lessons in Story Design from Pixar's Creative Team.

5. Coveney, N. (2017, November 29). Forbes. Retrieved from

https://www.forbes.com/sites/forbescoachescouncil/2017 /11/29/how-to-harness-the-power-ofcollaboration/\#45a6cce63d65

6. Fatimah Shukri. (2016). RUANG, MASA DAN SEBAB AKIBAT DALAM NARATIF FILEM. Jurnal Melayu, 238.

7. G.Peter, B. (2016, March 21). Medium. Retrieved from 6 Rules of Great Storytelling (As Told by Pixar):
https://medium.com/@Brian_G_Peters/6-rules-of-greatstorytelling-as-told-by-pixar-fcc6ae225f50

8. Hashim, A. H. (2015, January 24). Punca siri animasi hilang. (U. online, Interviewer)

9. Ismail, I. (2018, August). Malaysia's father of animation talks about his passion, state of animation industry. Retrieved from New Straits Times: https://www.nst.com.my/lifestyle/bots/2017/08/273598/ malaysias-father-animation-talks-about-his-passion-stateanimation

10. James, S. (2011, March 7). Writer's Digest. Retrieved from 3 Secrets to Great Storytelling: http://www.writersdigest.com/writing-articles/bywriting-goal/write-first-chapter-get-started/3-secrets-togreat-storytelling

11. Johari, F. (2015, June 30). Says.com. Retrieved from http://says.com/my/seismik/belanja-rm4-juta-kutipanhanya-rm37-ribu-apa-dah-jadi-dengan-filem-oh-lala

12. Miller, E. (2011). Theories of Story and Storytelling. 1.

13. Muthalib, H. (Director). (1980). Hikayat Sang Kancil [Motion Picture].

14. Muthalib, H. (2017, August 28). Malaysia's father of animation talks about his passion, state of animation industry. (I. Ismail, Interviewer)

15. Razak, N. (Director). (2018). Upin dan Ipin [Motion Picture].

16. Rose, A. (n.d.). Principle of animation.

17. Sallehudin, D. A. (Director). (2015). Oh! La La [Motion Picture].

18. Surtees, N. (2016). Pixar's lessons in Design Thinking. ticktockcrocodail. (2010). Principles of Animation.

19. Yasin, M. U. (Director). (2018). Ejen Ali [Motion Picture]. 